\title{
Espécies lenhosas de Papilionoideae (Leguminosae) na Estação Ambiental de Volta Grande, Minas Gerais, Brasil ${ }^{1}$
}

\author{
Fabiana Luiza Ranzato Filardi ${ }^{2,3,4}$, Flávia Cristina Pinto Garcia ${ }^{3}$ \\ \& Rita Maria de Carvalho-Okano ${ }^{3}$
}

\begin{abstract}
RESUMO
(Espécies lenhosas de Papilionoideae (Leguminosae) na Estação Ambiental de Volta Grande, Minas Gerais, Brasil) Neste trabalho apresentamos o estudo taxonômico das Papilionoideae lenhosas em formações de cerrado e de floresta semidecidual na Estação Ambiental de Volta Grande. A área de estudo, localizada no Triângulo Mineiro, faz parte do complexo da Usina Hidrelétrica Estadual de Volta Grande, reúne 391ha e retrata 30 anos de regeneração natural. Foram registrados 14 táxons reunidos em 11 gêneros e quatro tribos: Dalbergieae, com Centrolobium, Dalbergia, Machaerium e Platypodium; e Sophoreae, com Acosmium, Bowdichia, Myroxylon e Ormosia foram as tribos mais representativas, enquanto Dipterygeae, está representada por Dipteryx e Pterodon; e Robinieae, apenas por Sesbania. O gênero mais expressivo foi Machaerium, com três espécies, seguido por Acosmium, com duas, enquanto que os demais gêneros foram representados por uma espécie cada. Chave para identificação, descrições e ilustrações dos táxons encontrados são apresentadas além de comentários sobre a distribuição geográfica dos mesmos.
\end{abstract}

Palavras-chave: Leguminosae, Papilionoideae, florística, Cerrado, Triângulo Mineiro.

\section{Abstract}

(Woody species of Papilionoideae (Leguminosae) at the Estação Ambiental de Volta Grande, Minas Gerais, Brazil) This work is a taxonomic study of woody taxa of Papilionoideae in "cerrado" and seasonal semideciduous forest at the Estação Ambiental de Volta Grande. This environmental station is localized within the Triângulo Mineiro, to the southwest of the state of Minas Gerais, and belongs to the Companhia Energética de Minas Gerais, covering $391 \mathrm{ha}$ and portraying 30 years of natural regeneration. Fourteen taxa distributed in 11 genera and four tribes were reported for the subfamily. Dalbergieae, with Centrolobium, Dalbergia, Machaerium and Platypodium; and Sophoreae, with Acosmium, Bowdichia, Myroxylon and Ormosia were the most representative tribes, followed by Dipterygeae, with Dipteryx and Pterodon and Robinieae, with Sesbania. Three species of Machaerium, and two species of Acosmium were found, while the other genera were represented by one species each. An identification key, descriptions and illustrations are presented for the taxa studied, as well as comments regarding their geographical distribution.

Key words: Leguminosae, Papilionoideae, floristic, Cerrado, Triângulo Mineiro.

\section{INTRODUÇÃo}

O domínio do cerrado cobre, aproximadamente, $2.000 .000 \mathrm{~km}^{2}$ (Coutinho 2002) que abrangem mais de $20^{\circ}$ de latitude (Ratter et al. 1997). Considerado o segundo maior bioma do Brasil, atualmente seus remanescentes de vegetação primária correspondem somente a $20 \%$ da área original e apenas 6,2\% estão localizados em áreas de preservação (Myers et al. 2000). Com diversidade florística estimada em 10.000 espécies, sendo 4.400 endêmicas, o cerrado é um dos 25 ecossistemas mais ricos e mais ameaçados do planeta (Myers et al. 2000; Pennington et al. 2000). Sua vegetação caracteriza-se pela existência de fitofisionomias ecotonais entre dois extremos fisionômicos: $\mathrm{o}$ cerradão apresenta predomínio do componente arbustivo-arbóreo, enquanto no campo limpo o estrato lenhoso é inexpressivo (Coutinho 2002).

Leguminosae é considerada a família de maior riqueza florística no cerrado ( $25 \%$ dos táxons), seguida por Asteraceae (16\%), Orchidaceae (14\%) e Poaceae (11\%), famílias

Artigo recebido em 08/2006. Aceito para publicação em 02/2007.

${ }^{1}$ Parte da Dissertação de Mestrado da primeira autora, Programa de Pós-graduação em Botânica, Universidade Federal de Viçosa.

${ }^{2}$ Bolsista do convênio n 315 SIF - CEMIG / ANEEL (registro P \& D 042).

${ }^{3}$ Universidade Federal de Viçosa, Depto. Biologia Vegetal, Avenida P. H. Rolphs s/nº 36571-000, Viçosa, MG, Brasil.

${ }^{4}$ Autor para correspondência: ffilardi@jbrj.gov.br 
expressivas apenas para a flora herbáceosubarbustiva (Mendonça et al. 1998). Assim, Leguminosae é importante para a dinâmica das comunidades nas diferentes fitofisionomias, tanto extremas quanto intermediárias (campo sujo, campo cerrado e cerrado sensu stricto), que compõem o bioma (Eiten 1972; Warming \& Ferri 1973; Mendonça et al. 1998).

Papilionoideae reúne cerca de 13.800 espécies em 483 gêneros e 28 tribos (Lewis et al. 2005) e, segundo Mendonça et al. (1998) está representada no cerrado por 398 táxons, que representam $46 \%$ do total citado para Leguminosae neste bioma. Caracteriza-se por folhas pinadas, nunca bipinadas, flores papilionáceas com simetria zigomorfa e prefloração imbricada vexilar havendo, porém, exceções nas tribos Sophoreae e Swartzieae que apresentam flores actinomorfas (Polhill \& Raven 1981; Lewis et al. 2005).

Originalmente, o cerrado cobria mais de 30 milhões de hectares em Minas Gerais (Laca-Buendia \& Brandão 1995), porém a partir da década de setenta, principalmente no Triângulo Mineiro, imensas áreas de vegetação nativa foram degradadas para dar lugar à agropecuária e à monocultura. A Estação Ambiental de Volta Grande (EAVG), após 30 anos de regeneração natural, apresenta-se como um dos poucos refúgios da região de Uberaba, que segundo Drummond et al. (2005) reúne áreas prioritárias para a conservação e investigação científica no estado, pois apresenta alta importância biológica, alto grau de ameaça e número reduzido de unidades de conservação.

Estudos específicos sobre Leguminosae em Minas Gerais são restritos principalmente a áreas do domínio da mata atlântica (Lima 2006; Bortoluzzi et al. 2004; Bosqueti 2004; Nunes 2003; Mendonça Filho 1996) e de campos rupestres (Dutra 2005; Queiroz 2004). Devido à importância da família para o cerrado, este trabalho teve como objetivo realizar o estudo taxonômico dos representantes lenhosos da subfamília Papilionoideae na EAVG, a única área de compensação ambiental da Companhia Energética de Minas Gerais (CEMIG) implantada em conjunto com o complexo industrial de produção de energia. Apresentamos chave analítica para a identificação dos táxons, descrições e ilustrações dos mesmos, além de nomes populares, comentários sobre distribuição geográfica e preferência por habitat na EAVG.

\section{Material e Métodos}

A Estação Ambiental de Volta Grande faz parte do complexo da Usina Hidrelétrica Estadual de Volta Grande, que pertence à CEMIG e localiza-se a $40 \mathrm{~km}$ de Uberaba, entre os municípios de Conceição das Alagoas (MG) e Miguelópolis (SP) (2000'-2001'S e $48^{\circ} 12^{\prime}-48^{\circ} 15^{\prime} \mathrm{W}$ ) (Fig. 1). Nesta região do Triângulo Mineiro, o clima é do tipo Cwa, de acordo com a classificação de Köppen, com temperatura média anual entre $22^{\circ} \mathrm{C}$ e $24^{\circ} \mathrm{C}$, estação seca bem definida, de maio a outubro, e precipitação média anual de $1.550 \mathrm{~mm}$ (CPTEC/INPE 2006). A área de estudo apresenta altitude média de $524 \mathrm{~m}$ e relevo de baixa declividade, característico do curso oeste do rio Grande, na divisa dos estados de Minas Gerais e São Paulo, com trechos de margens alagadiças e muitas lagoas marginais (Vaz et al. 2000). Criada em 1976, a EAVG reúne 391 ha, sendo que cerca de 190 ha de cerrado e 85 ha de floresta estacional semidecidual encontram-se em franco processo de sucessão secundária, existindo ainda 30 ha de várzea que são muito importantes para a fauna presente na área (Fig. 1).

Foram realizadas 10 expedições para a coleta de material botânico, entre setembro de 2002 a novembro de 2005. Com a finalidade de cobrir a variação fisionômica da vegetação, foram estabelecidas seis trilhas em formações de cerrado e quatro em áreas de floresta estacional semidecidual. A trilha 1 representa a área de cerrado sensu stricto em estágio de regeneração mais avançado, com cerca de 60 ha, as trilhas 2, 3 e 4 representam áreas mais alteradas de cerrado sensu stricto, enquanto que as trilhas 5 e 6 são manchas de 
cerradão, que reúnem aproximadamente 16ha. Nas formações de floresta estacional semidecidual, as trilhas 7 e 8 são adjacentes à área de várzea, enquanto que as trilhas 9 e 10 localizam-se nas margens mineira e paulista do reservatório, respectivamente (Fig. 1).

O material botânico foi coletado e herborizado conforme as técnicas de Fidalgo \& Bononi (1984), registrado e incorporado no acervo do herbário VIC. A terminologia morfológica adotada nas descrições foi baseada na literatura taxonômica sobre a subfamília e nos trabalhos de Radford et al. (1974) e Polhill
\& Raven (1981) e os tipos de frutos em Barroso et al. (1999). A classificação adotada para tribos e gêneros foi a de Lewis et al. (2005). Os táxons são apresentados em ordem alfabética dentro de cada gênero, sendo fornecidos comentários sobre distribuição geográfica e preferência por habitat na EAVG após cada descrição. As ilustrações, das características vegetativas e reprodutivas, foram realizadas a partir de materiais herborizados e /ou fixados em álcool 70\%, com o auxílio de uma câmara clara acoplada ao estereomicroscópio Olympus.

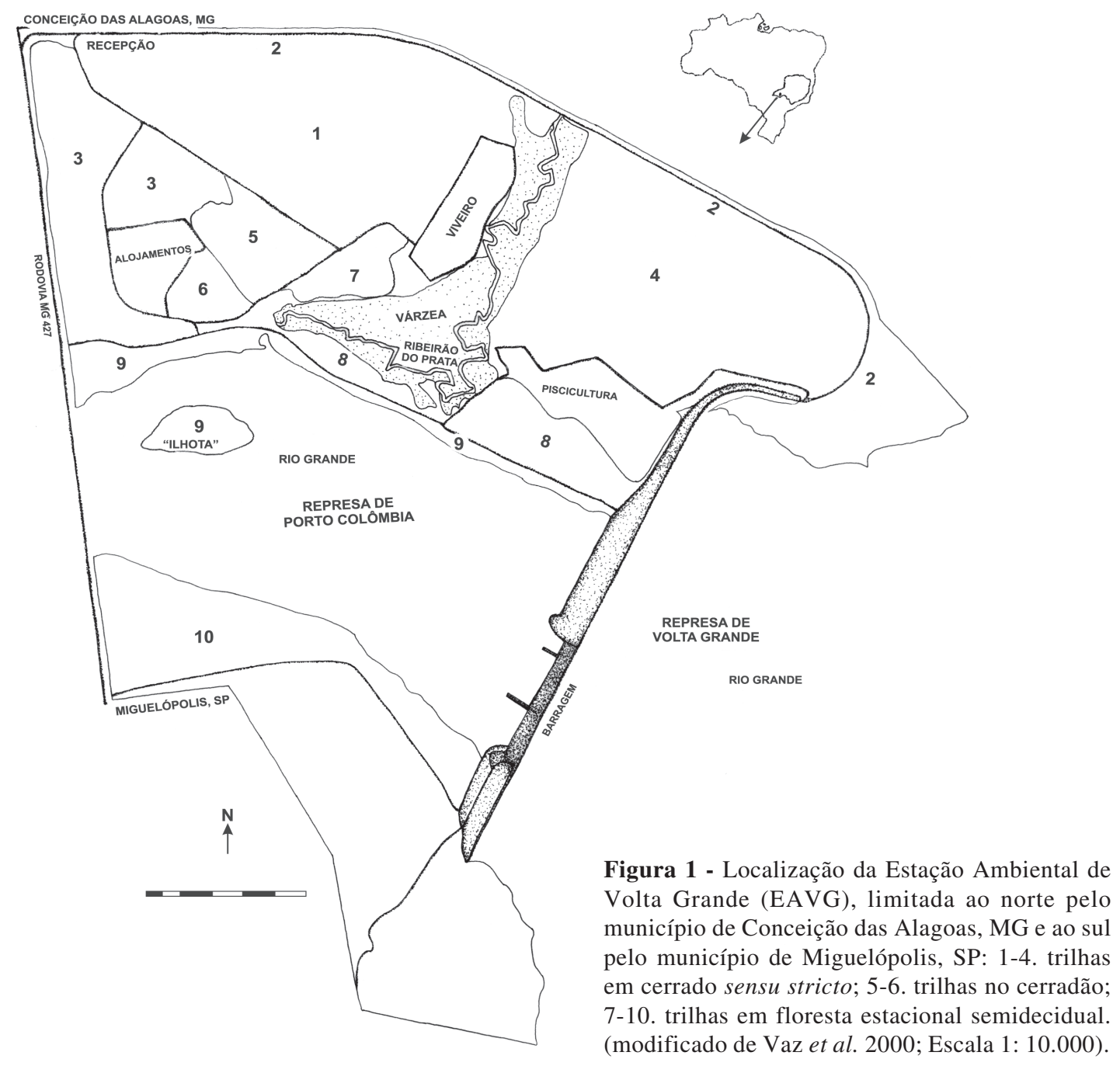




\section{Resultados e Discussão}

Na EAVG, foram identificados 14 táxons nativos de Papilionoideae, pertencentes a 11 gêneros e quatro tribos: Dalbergieae (Centrolobium, Dalbergia, Machaerium e Platypodium) e Sophoreae (Acosmium, Bowdichia, Myroxylon e Ormosia) foram as tribos mais representativas, seguidas por Dipterygeae (Dipteryx e Pterodon) e Robinieae (Sesbania). Machaerium, com três espécies, e Acosmium, com duas, foram os gêneros mais expressivos, enquanto que os demais foram representados por apenas uma espécie. A maioria dos táxons $(86 \%)$ apresentou hábito arbóreo, sendo apenas dois deles arbustivos. Todos os táxons tratados já foram citados para a flora do cerrado (Mendonça et al. 1998). Na EAVG, a maioria das espécies (64\%) mostrouse restrita às formações de cerrado, uma ocorreu apenas na mata e quatro espécies (29\%) ocorreram tanto nas áreas de cerrado, quanto nas de floresta estacional semidecidual.

\section{Chave para a identificação das Papilionoideae lenhosas ocorrentes na Estação Ambiental de Volta Grande, MG}

1. Folhas paripinadas.

2. Árvore; raque foliar alada, glabra; folíolos 4-6 pares, glabros, nervura principal excêntrica; cálice com 2 lacínias petalóides; fruto drupa 5.1. Dipteryx alata

2'. Arbusto; raque foliar não alada, serícea; folíolos 17-22 pares, face abaxial serícea, nervura principal central; cálice com 5 lacínias semelhantes, não petalóides; fruto legume nucóide 11.1. Sesbania virgata

1'. Folhas imparipinadas.

3. Folíolos alternos.

4. Lâmina foliar com pontuações e traços translúcidos; fruto sâmara, ala com nervura submediana 7.1. Myroxylon peruiferum

4'. Lâmina foliar sem pontuações e traços translúcidos; fruto legume samaróide ou sâmara, ala sem nervura submediana.

5. Folíolos 9-11; legume samaróide

2.1. Bowdichia virgilioides

5'. Folíolos 13-23; sâmara.

6. Folíolos ovados a orbiculares, base cordada, ápice arredondado; androceu monadelfo; região seminífera central 4.1. Dalbergia miscolobium

6'. Folíolos oblongos a elípticos, base oblíqua a obtusa, ápice emarginado; androceu poliadelfo; região seminífera distal .... 9.1. Platypodium elegans

3'. Folíolos opostos a subopostos.

7. Folíolos 3-13.

8. Plantas totalmente glabras; corola actinomorfa ......1.2. Acosmium subelegans

8'. Plantas densamente indumentadas; corola actinomorfa ou zigomorfa.

9. Ápice do folíolo retuso; corola actinomorfa; legume samaróide

9'. Ápice do folíolo agudo; corola zigomorfa; sâmara ou legume.

1.1. Acosmium dasycarpum ssp. dasycarpum

10. Folíolo com pontuações resiníferas na face abaxial; fruto sâmara, região seminífera proximal equinada; semente não bicolor, castanhoavermelhada

3.1. Centrolobium tomentosum

10'. Folíolo sem pontuações resiníferas na face abaxial; fruto legume; semente bicolor, vermelha e preta 8.1. Ormosia fastigiata

7'. Folíolos 15 ou mais.

11. Estípulas espinescentes. 
12. Arbusto escandente; estípulas espinescentes recurvadas; folíolos 23-43

6.1. Machaerium aculeatum

12'. Árvore; estípulas espinescentes retilíneas ou sobrepostas; folíolos 37-53

6.3. Machaerium hirtum

11'. Estípulas não espinescentes.

13. Apêndice foliar terminal presente; raque foliar tomentosa; folíolos 23-37; fruto criptossâmara . 10.1. Pterodon emarginatus

13'. Apêndice foliar terminal ausente; raque foliar glabra; folíolos 15-17; fruto sâmara . 6.2. Machaerium acutifolium

1. Acosmium Schott., Linn. Syst. Veg. (ed.16) 4: 406. 1827.

\subsection{Acosmium dasycarpum ssp. dasycarpum} (Vog.) Yakov., Not. Roy. Bot. Gard. Edinb. 29: 351.1969.

Fig. 2 a-c

Arvoretas 2,5-3 m alt. Ramos angulosos, suberosos, vilosos. Folhas imparipinadas; estípulas lanceoladas, ca. $3 \mathrm{~mm}$ compr., lanuginosas, caducas; pecíolo $2,5-3,3(-3,8) \mathrm{cm}$ compr., lanuginoso; raque $(2,3-)$ 4,5-6,6 cm compr., lanuginosa; folíolos 3-5 (-7), (3,3-) $4,2-8,5 \times 2-4 \mathrm{~cm}$, opostos a subopostos, elípticos, base obtusa, raro oblíqua, ápice retuso, face adaxial ciliada, face abaxial lanuginosa. Inflorescências em panículas, axilares, terminais, pedúnculo 11-15 mm compr., raque 6-8 cm compr., vilosa; brácteas não observadas, bractéolas lanceoladas, ca. 1,5 mm compr., lanuginosas. Flores actinomorfas, hipanto ca. 1,5 mm compr., pedicelo $2-3 \mathrm{~mm}$ compr.; cálice campanulado, 5 × $6 \mathrm{~mm}$, 5-laciniado, esparsamente lanuginoso; corola amareloalaranjada, glabra, pétalas 3,5-5 × 2-3,2 mm, base atenuada, unguícula 2,5-3 mm compr., ápice obtuso; androceu dialistêmone, ca. $9 \mathrm{~mm}$ compr., 10 estames, anteras com deiscência longitudinal; ovário ca. $5 \mathrm{~mm}$ compr., lanuginoso; estípite ca. $2 \mathrm{~mm}$ compr.; estilete ca. 4,5 mm compr.; estigma inconspícuo, oblíquo. Legumes samaróides, 3,2-5,2 × 2,1$2,5 \mathrm{~cm}$, elípticos, estípite 7-11 mm compr., base atenuada, cálice persistente, ápice obtuso, mucronulado, lanuginosos, castanho-dourados; sementes 1-2 (3), castanho-claras.

Material examinado: trilha 2, 24.II.2003, fr., F. L. R. Filardi et al. 214 (VIC); idem, 9.XII.2003, fl.e fr., $F$. L. R. Filardi et al. 396 (VIC); trilha 3, 7.III.2004, fr., F. L. R. Filardi et al. 459 (VIC).
Nome popular: perobinha, amargoso, chapada. Restrita ao Brasil (Yakovlev 1969; ILDIS 2005), ocorre em Minas Gerais, Rio de Janeiro, São Paulo (Yakovlev 1969), Bahia (Lewis 1987) e no Planalto Central (Lorenzi 2002b), ocupando principalmente áreas de cerrado (Yakovlev 1969). A espécie é frequiente e restrita às áreas de cerrado sensu stricto na EAVG e, segundo Cordeiro (2002), apresenta potencial para a recuperação de áreas degradadas. Floresceu entre setembro e dezembro e frutificou entre janeiro e março, apresentando flores e frutos em dezembro.

1.2 Acosmium subelegans (Mohlenbr.) Yakov., Not. Roy. Bot. Gard. Edinb. 29: 353. 1969.

Fig. 2 d,e

Árvores ca. $5 \mathrm{~m}$ alt. Ramos angulosos, suberosos, lenticelados, glabros. Folhas imparipinadas; estípulas não observadas; pecíolo 4,3-7,3 cm compr., glabro; raque 5,6-10 cm compr., glabra; folíolos (5-) 7-9, 3,1-5,4 × 2,4-3,5 cm, opostos a subopostos, ovados, base arredondada, raro obtusa, ápice retuso, glabros. Inflorescências em panículas, axilares, terminais, pedúnculo 1,5-3,2 cm compr., raque 5,5-7,5 cm compr., glabra; brácteas não observadas, bractéolas lanceoladas, ca. $1 \mathrm{~mm}$ compr, glabras. Flores actinomorfas, hipanto ca. $1 \mathrm{~mm}$ compr.; pedicelo ca. $3 \mathrm{~mm}$ compr.; cálice campanulado, ca. $4 \times 5 \mathrm{~mm}$, 5-laciniado, glabro; corola amarelo-clara, glabra; pétalas $4-5 \times 3-3,5 \mathrm{~mm}$, base atenuada, unguícula 2-3 mm compr., ápice obtuso; androceu dialistêmone, ca. $1 \mathrm{~cm}$ compr., 10 estames, anteras com deiscência longitudinal; ovário ca. $2 \mathrm{~mm}$ compr., glabro, estípite ca. $3 \mathrm{~mm}$ compr.; 
estilete ca. 2,5 mm compr.; estigma inconspícuo, crestado. Frutos não observados.

Material examinado: trilha 2, 24.IX.2002, fl., F. L. R. Filardi et al. 94 (VIC); idem, 8.XI.2005, fl., F. L. R. Filardi \& F. C. P. Garcia 673 (VIC); idem, 676 (VIC).

Nome popular: amendoim-falso, chapadinha.

Restrita ao sul da América do Sul (Yakovlev 1969; ILDIS 2005), no Brasil, ocorre nos estados de Goiás, Mato Grosso, Mato Grosso do Sul (Lorenzi 2002a), Minas Gerais, São Paulo e Paraná, ocupando principalmente áreas de cerrado (Yakovlev 1969). Na EAVG, a espécie é frequiente ao longo da estrada asfaltada que leva da recepção à barragem (trilha 2), mas também ocorre na trilha 1, área em estágio de regeneração mais avançado (Fig. 1). A floração foi observada entre setembro e dezembro.

2. Bowdichia Kunth., Nov. Gen. Sp. (folio ed.) 6: 295.1823.

2.1 Bowdichia virgilioides Kunth., Nov. Gen. Sp. 6: 376. 1823.

Fig. 2 f,g

Árvores ca. $11 \mathrm{~m}$ alt. Ramos cilíndricos a levemente angulosos, levemente suberosos, espessados na inserção das folhas, puberulentos. Folhas imparipinadas; estípulas não observadas; pecíolo 1,4-2,9 cm compr., puberulento; raque $8,8-9,8 \mathrm{~cm}$ compr., puberulenta a esparsamente tomentosa; folíolos (7-) 9-11, 5,2-7,5 × 1,5-2,2 cm, alternos, oblongos, base obtusa, ápice emarginado, face adaxial glabra, lustrosa, face abaxial esparsamente serícea, tricomas esparsos sobre as nervuras secundárias e terciárias. Flores não observadas. Legumes samaróides, 5,3-7,2 $\times$ 1,5-1,7 cm, oblongos, estípite 9-11 mm compr., ala vexilar proeminente, ca. $2 \mathrm{~mm}$ larg., base atenuada, cálice persistente, ápice obtuso, mucronulado, glabros, castanho-avermelhados; sementes 3-10, alaranjadas a amarelas.

Material examinado: trilha 1, 23.IX.2002, fr., F.L.R. Filardi et al. 70 (VIC).

Nome popular: sucupira-do-cerrado, sucupira-preta.

A espécie é nativa da América do Sul (ILDIS 2005) e no Brasil, pode ser encontrada nos estados da Bahia (Lewis 1987), Pará, Goiás, Mato Grosso, Mato Grosso do Sul, Minas Gerais e São Paulo (Lorenzi 2002a). Ocorre, geralmente, em formações de cerrado (Ratter et al. 2003), mas é citada também para áreas de campos rupestres (Zappi et al. 2003) e de restinga (Lewis 1987). Na EAVG, a espécie é freqüente e restrita à trilha 1 , que representa a área de cerrado sensu stricto em estágio de regeneração mais avançado da área de estudo (Fig. 1). A capacidade para a associação simbiótica com bactérias diazotróficas foi atestada em isolados provenientes do cerrado (Cordeiro 2002) e de sua casca foram isoladas substâncias ativas contra a malária (Deharo et al. 2001). A frutificação foi observada em setembro.

3. Centrolobium Mart. ex Benth., Comm. Legum. Gen. 31. 1837.

3.1 Centrolobium tomentosum Guillem. ex Benth., J. Bot. (Hooker) 2: 66. 1840.

Fig. $2 \mathrm{~h}-\mathrm{j}$

Árvores 6-7 m alt. Ramos cilíndricos a levemente angulosos, canaliculados, lenticelados, tomentosos. Folhas imparipinadas; estípulas lanceoladas, ca. $12 \mathrm{~mm}$ compr., tomentosas, caducas; pecíolo (4,7-) 5,4-8,6 (-9,5) cm compr., tomentoso, pontos resiníferos dourados; raque (6,5-) 10,5-19,6 cm compr., tomentosa, pontos resiníferos dourados; folíolos $7-13,5,8-13,6 \times 3-6 \mathrm{~cm}$, opostos a subopostos, elípticos a oblongos, base obtusa, ápice cuspidado, face adaxial levemente tomentosa, face abaxial tomentosa, pontos resiníferos dourados em depressões do limbo. Inflorescências em panículas, axilares, terminais, pedúnculo 1-2,7 $\mathrm{cm}$ compr., raque 6-10,5 cm compr., vilosa; brácteas não observadas, bractéolas lanceoladas, 7-10 mm compr., tomentosas, pontos resiníferos dourados. Flores zigomorfas; pedicelo ca. $4 \mathrm{~mm}$ compr.; cálice campanulado, 15-17 × 7-8 mm, 4-laciniado, tomentoso, pontos resiníferos dourados; corola amarela, glabra; vexilo $18-19 \times 16 \mathrm{~mm}$, base recurvada, 


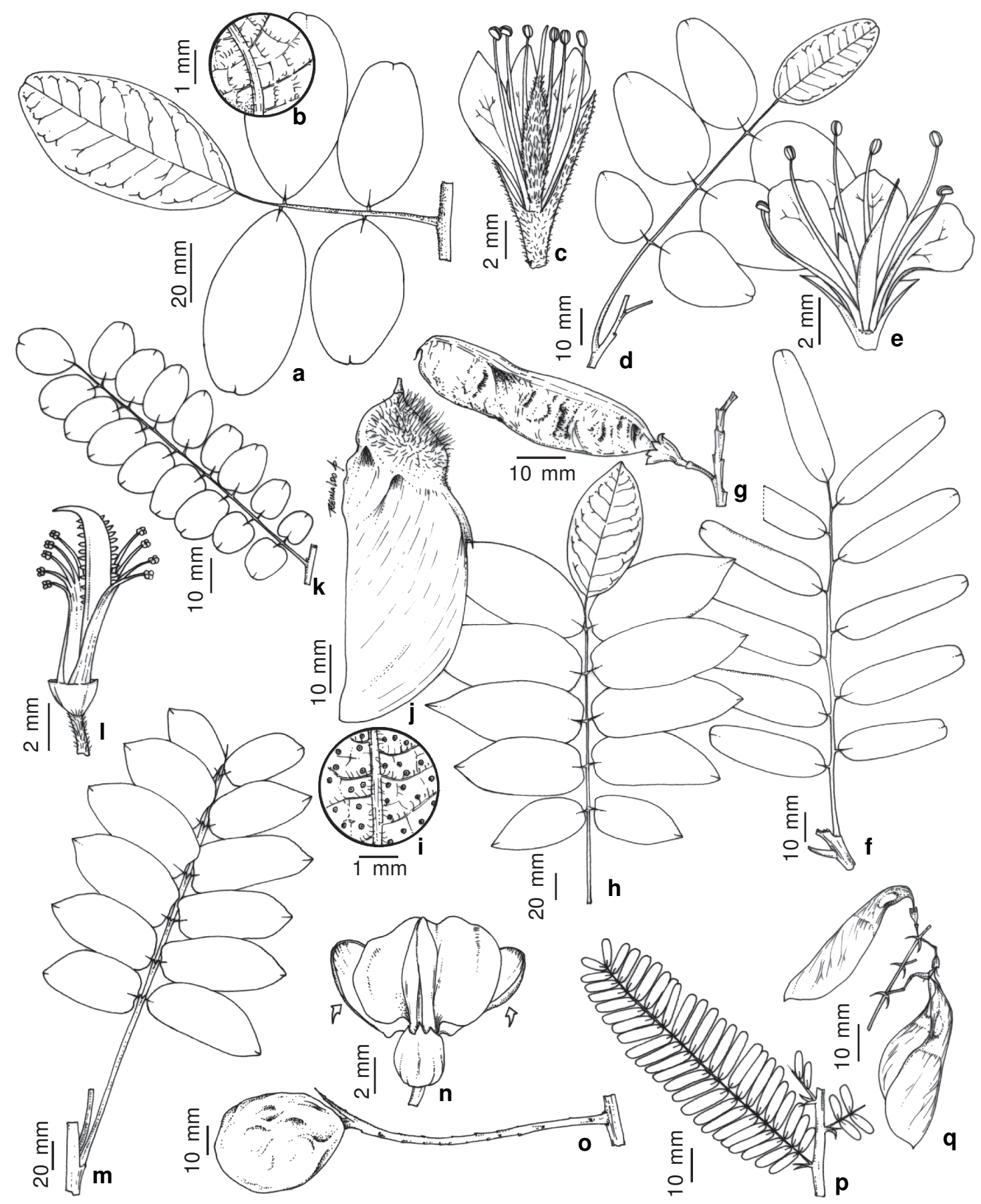

Figura 2 - a-c. Acosmium dasycarpum ssp. dasycarpum - a. folha; b. indumento dos folíolos; c. flor em corte longitudinal (Filardi 396); d-e. Acosmium subelegans - d. folha; e. flor em corte longitudinal (Filardi 94); f-g. Bowdichia virgilioides - f. folha; g. fruto (Filardi 70); h-j. Centrolobium tomentosum - h. folha; i. pontos resiníferos na face abaxial dos folíolos; j. fruto (Filardi 345); k-1. Dalbergia miscolobium - k. folha; 1. flor sem o perianto (Filardi 445); m-o. Dipteryx alata m. folha; n. flor com sépalas petalóides (setas) (Filardi 196); o. fruto (Filardi 440); p-q. Machaerium aculeatum p. folha; q. frutos (Filardi 513). 
auriculada, ápice obtuso; alas ca. $14 \times 7 \mathrm{~mm}$, base oblíqua, auriculada, unguícula 3-4 mm compr.; pétalas da carena ca. $14 \times 6 \mathrm{~mm}$, base oblíqua, auriculada, unguícula ca. 4 mm compr.; androceu monadelfo, ca. $19 \mathrm{~mm}$ compr., 10 estames, anteras com deiscência longitudinal; ovário ca. $7 \mathrm{~mm}$ compr., densamente tomentoso, pontos resiníferos dourados; estilete ca. $12 \mathrm{~mm}$ compr.; estigma inconspícuo, crestado. Sâmaras, 13-15 × 5-5,5 cm, base oblíqua, espinho estilar lateral, ápice obtuso, tomentosas, castanhas, região seminífera proximal, 3,54,3 cm larg., equinada, ala 5-5,5 cm larg.; semente castanho-avermelhada.

Material examinado: trilha 2, 6.III.2004, fl., F. L. R. Filardi et al. 435 (VIC); trilha 3, 28.I.2003, fl., F. L. R. Filardi \& S. L. Faria 174(VIC); idem, 29.IX.2003, fr., F. L. R. Filardi et al. 345 (VIC).

Nome popular: araribá, araribá-rosa, araruvá.

Restrita ao Brasil, ocorre desde São Paulo até a Bahia, avançando para o interior até Goiás, ocupando principalmente áreas de floresta estacional semidecidual e de cerrado (Lima 1988). Na EAVG, a espécie é freqüente nas áreas mais alteradas de cerrado sensu stricto, principalmente às margens da estrada asfaltada (trilha 2) próximo a entrada para a piscicultura e para a barragem (Fig. 1). Produz grande quantidade de sementes viáveis amplamente disseminadas pelo vento, apresentando grande vigor nos estágios iniciais de secessão secundária (Lorenzi 2002a). Floresceu entre janeiro e março e frutificou em setembro.

4. Dalbergia L. f., Suppl. P1. 52: 316. 1782.

4.1 Dalbergia miscolobium Benth. in Mart.; Eichl. et Urb., Fl. bras. 15 (1): 222. 1862.

Fig. 2 k, 1

Árvores 3,5-7 m alt. Ramos cilíndricos, canaliculados, lenticelados, pulverulentos, esparsamente ciliados a glabrescentes. Folhas imparipinadas; estípulas não observadas; pecíolo (7-) 10-14 mm compr., glabro; raque 6,8-10,6 cm compr., glabrescente; folíolos (15-) 17-21, 11-23 × 10-14 mm, alternos, ovados, orbiculares, base cordada, ápice arredondado, faces adaxial e abaxial glabrescentes. Inflorescências em panículas, axilares, terminais, pedúnculo 8-12 mm compr., raque 2,3-5,3 cm compr., tomentosa; brácteas obovadas, ca. $2 \mathrm{~mm}$ compr., seríceas, caducas, bractéolas ovado-elípticas, ca. 1,8 mm compr., tomentosas, caducas. Flores zigomorfas, hipanto ca. $1 \mathrm{~mm}$ compr.; pedicelo ca. $4 \mathrm{~mm}$ compr.; cálice bilabiado, ca. $4 \times 3 \mathrm{~mm}, 5$ laciniado, 2 sépalas adaxiais fundidas quase completamente, glabro, ápice das sépalas indumentado; corola roxa, glabra; vexilo ca. 6 $\times 8 \mathrm{~mm}$, base truncada, unguícula ca. $2,5 \mathrm{~mm}$ compr., ápice obcordado; alas ca. 5,5 ×4 mm, base auriculada, unguícula ca. 2 mm compr.; pétalas da carena ca. $5 \times 3 \mathrm{~mm}$, base oblíqua, unguícula ca. 2 mm compr.; androceu monadelfo, ca. 7 mm compr., 9-10 estames, anteras com deiscência transversal, apical; ovário ca. $2 \mathrm{~mm}$ compr., glabro, tricomas estrigosos na base e lateralmente, estípite ca. 2,5 mm compr.; estilete ca. $1 \mathrm{~mm}$ compr.; estigma inconspícuo, crestado. Sâmaras, 3,5-6 × 1,7-2,2 cm, elípticas, base e ápice obtusos, glabras, castanhas, região seminífera central, $1-1,8 \mathrm{~cm}$ larg.; semente castanha.

Material examinado: trilha 1, 6.V.2005, fr., F. L. R. Filardi et al. 581 (VIC); trilha 2, 6.III.2004, fl., F. L. R. Filardi et al. 445 (VIC); trilha 3, 24.II.2003, fl., F. L. R. Filardi et al. 205 (VIC).

Nome popular: caviúna-do-cerrado, jacarandá-do-cerrado.

Restrita ao Brasil, a espécie ocorre do Piauí até o Paraná, sendo característica da vegetação do cerrado (Carvalho 1997), mas ocupando também áreas de caatinga (Lewis 1987) e de campos rupestres (Zappi et al. 2003). Na EAVG, a espécie foi coletada nas trilhas de cerrado sensu stricto, sendo freqüente na área menos alterada (trilha 1) e estando em franca regeneração, principalmente, nas proximidades com o cerradão (trilha 5) (Fig. 1). Apresenta potencial para a recuperação de áreas degradadas pela capacidade de fixação biológica de nitrogênio quando em associação com bactérias do solo (Cordeiro 2002; Sprent 2001). Floresceu entre dezembro e março e frutificou entre maio e julho. 
5. Dipteryx Schreb., Gen. Pl. 2: 485. 1791.

5.1 Dipteryx alata Vog., Linnaea 11:383. 1837.

Fig. 2 m-o

Árvores 5-8 m alt. Ramos cilíndricos, lenticelados, glabros. Folhas paripinadas; estípulas não observadas; pecíolo 6,9-12,9 cm compr., glabro, alado; raque 13,3-19 cm compr., glabra, alada; folíolos 3-6 pares, 5,3-9,3 × 3$4,7 \mathrm{~cm}$, opostos a subopostos, elípticos, base cordada ou oblíqua, ápice agudo, glabros, nervura principal excêntrica. Inflorescências em panículas, axilares, terminais, pedúnculo 8-15 mm compr., raque $6,4-7,6 \mathrm{~cm}$ compr., densamente puberulenta; brácteas e bractéolas não observadas. Flores zigomorfas, hipanto ca. $2 \mathrm{~mm}$ compr., pedicelo ca. $3 \mathrm{~mm}$ compr.; 2 sépalas adaxiais petalóides e 3 sépalas abaxiais reduzidas, ca. $6 \times 5 \mathrm{~mm}$, internamente puberulentas, externamente com pontos glandulares; corola creme, glabra; vexilo ca. $7,5 \times 8 \mathrm{~mm}$, base truncada, unguícula ca. $1 \mathrm{~mm}$ compr., recurvada, ápice obcordato; alas ca. $6,5 \times 4 \mathrm{~mm}$, base oblíqua, unguícula ca. $1,2 \mathrm{~mm}$ compr.; pétalas da carena ca. $5 \times 3,2 \mathrm{~mm}$, base oblíqua, unguícula ca. 1,5 mm compr.; androceu monadelfo, ca. $6 \mathrm{~mm}$ compr., 10 estames, anteras com deiscência longitudinal; ovário ca. $2 \mathrm{~mm}$ compr., glabro, estípite ca. 2,5 mm compr.; estilete ca. 2,2 mm compr.; estigma inconspícuo, crestado. Drupas, 5,1-5,5 × 4,5-4,7 cm, piriformes, base e ápice arredondados, lenhosas, castanho-claras a pardas; semente castanho-escura.

Material examinado: trilha 2, 24.IX.2002, fr., F. L. R. Filardi et al. 91 (VIC); idem, 28.IX.2003, fr., F. L. R. Filardi et al. 300 (VIC); idem, 6.III.2004, fr., F. L. R. Filardi et al. 440 (VIC); trilha 3, 24.II.2003, fl., F. L. R. Filardi et al. 196 (VIC).

Nome popular: cumarú.

Restrita à América do Sul (ILDIS 2005), no Brasil é citada para os estados de Goiás, Mato Grosso, Mato Grosso do Sul, Minas Gerais e São Paulo (Lorenzi 2002a), ocupando principalmente áreas de cerrado (Ratter et al. 2003). Na EAVG, a espécie é abundante ao longo da estrada asfaltada que leva da recepção à barragem (trilha 2), ocorrendo de forma esporádica nas demais trilhas de cerrado sensu stricto. Seus frutos são comestíveis (polpa e semente) e apreciados pela população local, sendo o óleo da semente utilizado na perfumaria. Floresceu entre dezembro e fevereiro e frutificou entre março e setembro.

6. Machaerium Pers., Syn. Pl. 2 (2): 276. 1807.

6.1 Machaerium aculeatum Raddi, Mem. Soc. Ital. Modern. 18: 598. 1820. Fig. 2 p,q Arbustos escandentes ca. $2,5 \mathrm{~m}$ alt. Ramos cilíndricos, lenticelados, puberulentos a glabrescentes. Folhas imparipinadas; estípulas espinescentes, recurvadas, ca. $3 \mathrm{~mm}$ compr., glabras; pecíolo 3-6 mm compr., tomentoso; raque $7,6-11,3 \mathrm{~cm}$ compr., tomentosa; folíolos $23-43,8-15 \times 3-4 \mathrm{~mm}$, opostos a subopostos, oblongos, base oblíqua a obtusa, ápice emarginado, face adaxial glabra, face abaxial puberulenta. Flores não observadas. Sâmaras, ca. 4,4 × 1,2 cm, estípite 6-7 mm compr., base obtusa, cálice persistente, ápice obtuso, mucronulado, glabrescentes, castanho-claras com faixas tranversais enegrecidas e amareloesverdeadas, região seminífera proximal, 5$6 \mathrm{~mm}$ larg., enegrecida, ala 10-12 mm larg.; semente castanha.

Material examinado: trilha 4, 6.V.2004, fr., F. L.R. Filardi et al. 513 (VIC).

Nome popular: jacarandá-de-espinho.

As espécies $M$. aculeatum e $M$. hirtum são muito próximas e diferenciam-se, principalmente, pelo hábito escandente da primeira, que apresenta estípulas espinescentes recurvadas e folhas com 23-43 folíolos, enquanto que a segunda é estritamente arbórea, apresenta estípulas espinescentes retilíneas ou sobrepostas e folhas com 37-53 folíolos. Citada para a América Central e América do Sul (ILDIS 2005), no Brasil, M. aculeatum ocorre nos estados do Ceará, Pernambuco, Bahia (César et al. 2006), Minas Gerais, Rio de Janeiro e São Paulo (Bortoluzzi et al. 2004), ocupando áreas de mata atlântica (Mendonça Filho 1996), cerrado (Durigan et al. 2004) e campos rupestres (Zappi et al. 2003). A espécie é comum em áreas alteradas de cerrado, 
estando apta ao início da colonização devido à associação com bactérias para a fixação de nitrogênio (Cordeiro 2002). Na EAVG, a espécie ocorre apenas em uma trilha, que representa a área mais alterada de cerrado sensu stricto (trilha 4). A frutificação foi observada em maio.

6.2 Machaerium acutifolium Vog., Linnaea 11: 187.1837.

Fig. 3 a,b

Árvores 3-8 m alt. Ramos cilíndricos, canaliculados, lenticelados, glabros. Folhas imparipinadas; estípulas não observadas; pecíolo 4,3-6 cm compr., glabro; raque 14,519,4 cm, glabra; folíolos 15 (-17), 5,3-8,4×1,8$3,2 \mathrm{~cm}$, opostos, subopostos, raro alternos, lanceolados, base obtusa, ápice agudo, mucronulado, glabrescentes. Flores não observadas. Sâmaras, 7,5-9,1 × 1,9-2,2 cm, estípite 6-8 mm compr., base atenuada, ápice obtuso, glabras, castanho-claras, região seminífera proximal, 10-13 mm larg., enrugada, castanha, ala 19-22 mm larg.; semente castanho-escura.

Material examinado: trilha 1, 9. XI.2005, fr., F. L. R. Filardi \& F. C. P. Garcia 682 (VIC); idem, 683 (VIC); trilha 2, 8.XII.2003, fr., F. L. R. Filardi et al. 369 (VIC); trilha 3, 28.I.2003, fr., F. L. R. Filardi \& S. L. Faria 160 (VIC).

Nome popular: jacarandá-tã.

Restrita à América do Sul (ILDIS 2005), no Brasil, apresenta ampla distribuição, ocorrendo nos estados do Pará, Maranhão, Piauí, Ceará (Ducke 1949), Bahia (Lewis 1987), Goiás, Mato Grosso, Minas Gerais e São Paulo, predominantemente em formações de cerrado (Sartori \& Tozzi 1998). Na EAVG, a espécie é freqüente nas formações de cerrado sensu stricto, sendo abundante na trilha 1 , que representa a área em estágio mais avançado de regeneração (Fig. 1). A frutificação foi observada de setembro a janeiro.

6.3 Machaerium hirtum (Vell.) Stellfeld., Tribuna Farm. 14 (2): 246. $1946 . \quad$ Fig. 3 c-e

Árvores ca. $9 \mathrm{~m}$ alt. Ramos cilíndricos, lenticelados, glabrescentes. Folhas imparipinadas; estípulas espinescentes, retilíneas ou sobrepostas, 4-6 mm compr., puberulentas; pecíolo 3-6 mm compr., densamente tomentoso; raque 7,6-11,3 cm compr., puberulenta; folíolos $37-53,17-23 \times 4-5 \mathrm{~mm}$, opostos a subopostos, estreito-oblongos, base oblíqua, ápice retuso, mucronulado, glabros, face abaxial puberulenta. Inflorescências em panículas, axilares, terminais, pedúnculo 3-12 mm compr.; raque 2,2-7,5 cm compr., tomentosa; brácteas não observadas, bractéolas orbiculares, 1,5-2 mm compr., tomentosas. Flores zigomorfas, hipanto ca. 1,5 mm compr.; pedicelo ca. $3 \mathrm{~mm}$ compr.; cálice campanulado, $6 \times 4 \mathrm{~mm}, 5$-laciniado, tomentoso; corola violácea, serícea; vexilo ca. $10 \times 5 \mathrm{~mm}$, base atenuada, unguícula ca. $2 \mathrm{~mm}$ compr., ápice retuso; alas 10-13 × 4,5 mm, base truncada, unguícula ca. $3 \mathrm{~mm}$ compr.; pétalas da carena $8-13 \times 5 \mathrm{~mm}$, base oblíqua, unguícula ca. 3 mm compr.; androceu monadelfo, ca. $9 \mathrm{~mm}$ compr., 10 estames, anteras com deiscência longitudinal; ovário ca. $4 \mathrm{~mm}$ compr., velutino, estípite ca. 4 mm compr.; estilete ca. 4,2 mm compr.; estigma inconspícuo, crestado. Sâmaras, 4,4-5 × 1-1,2 cm, estípite ca. $9 \mathrm{~mm}$ compr., base atenuada, cálice persistente, ápice obtuso, mucronulado, esparsamente tomentosas, castanho-claras, região seminífera proximal, 5-6 mm larg., alas 1-1,2 cm larg.; semente castanha.

Material examinado: trilha 1, 20.IX.2002, fl., F. L.R. Filardi et al. 64 (VIC); trilha 4, 6.V.2005, fr., F. L. R. Filardi et al. 641 (VIC); trilha 8, 8.III.2004, fr., F. L. R. Filardi et al. 495 (VIC); trilha 9, 27.II.2003, fl.e fr., F. L. R. Filardi et al. 287 (VIC).

Nome popular: jacarandá-bico-de-pato.

Apresenta distribuição neotropical, sendo considerada uma espécie generalista (Morim 2006), e no Brasil ocorre nos estados do Rio de Janeiro, Minas Gerais, São Paulo, Goiás, Espírito Santo e Paraná (Sartori \& Tozzi 1998), ocupando áreas de mata atlântica (Morim 2006; Lima 1995) e de cerrado (Ratter et al. 2003). É uma das poucas espécies lenhosas de Papilionoideae que ocorrem tanto nas áreas de cerrado quanto nas de floresta estacional semidecidual da EAVG. A espécie é comum 


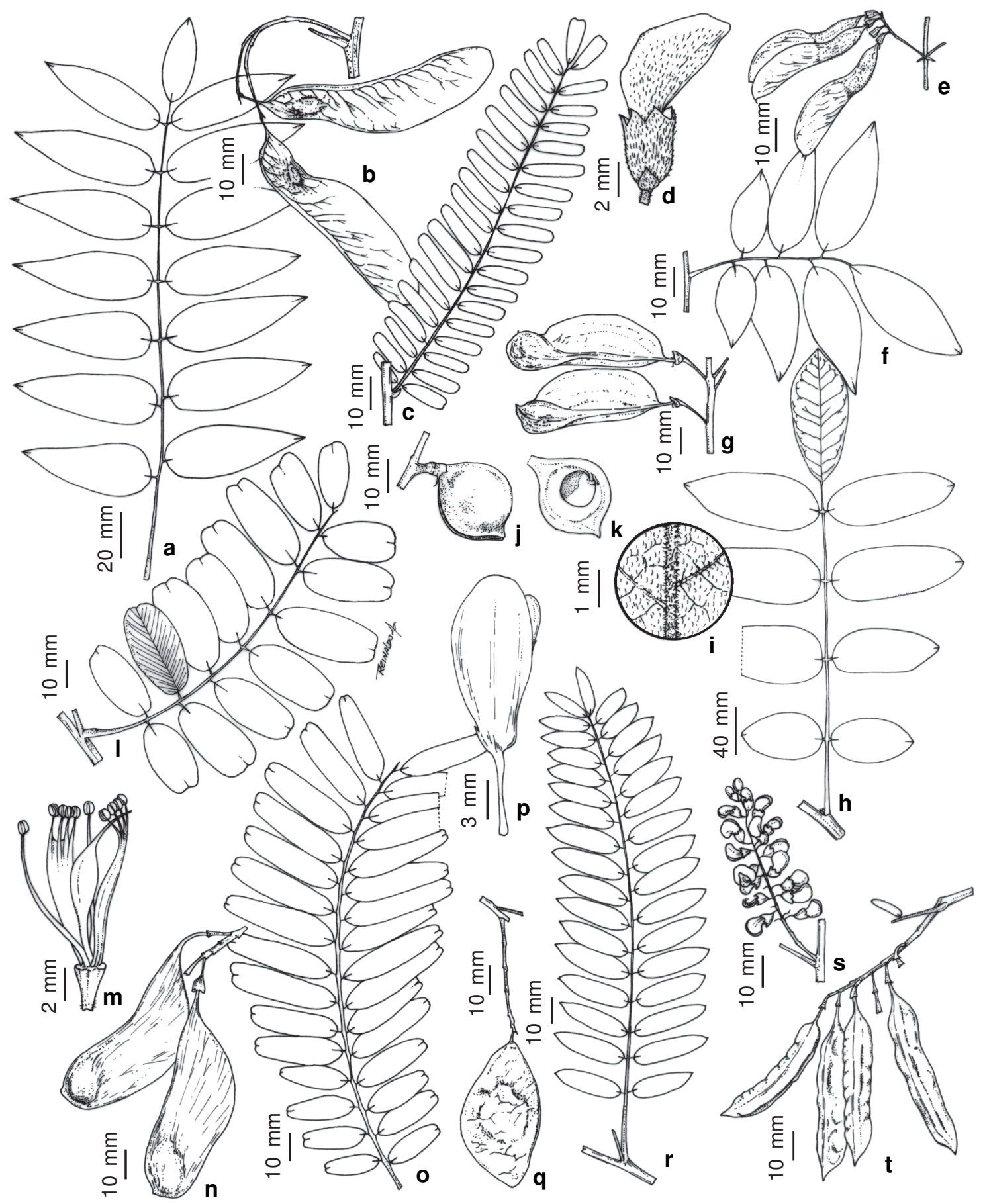

Figura 3 - a-b. Machaerium acutifolium - a. folha; b. frutos (Filardi 369); c-e. Machaerium hirtum - c. folha; d. flor (Filardi 64); e. frutos (Filardi 465); f-g. Myroxylon peruiferum - f. folha; g. frutos (Filardi 322); h-k. Ormosia fastigiata - h. folha; i. indumento na face abaxial dos folíolos; j. fruto; k. semente bicolor dentro do fruto (Filardi 99); 1-n. Platypodium elegans - 1. folha; m. flor sem o perianto (Filardi 334); n. frutos (Filardi 509); o-q. Pterodon emarginatus o. folha; p. botão floral com sépalas petalóides (Filardi 328); q. fruto (Filardi 211); r-t. Sesbania virgata - r. folha; s. inflorescência (Filardi 426); t. frutos (Filardi 206). 
nas áreas de cerrado sensu stricto (trilhas 1 e 4), porém mais freqüente nas formações florestais das trilhas 8 e 9 , localizadas próxima à várzea e na margem mineira do reservatório, respectivamente. Devido à capacidade de associação com microorganismos do solo, a espécie pode ser utilizada para a recuperação de áreas degradadas (Sprent 2001). Floresceu de setembro a janeiro e frutificou de março a maio, apresentando flores e frutos em fevereiro.

7. Myroxylon L. f., Suppl. Pl. 34: 233. 1781.

7.1 Myroxylon peruiferum L. f., Suppl. Pl. 34: 233. 1781.

Fig. 3 f,g

Árvores ca. $7 \mathrm{~m}$ alt. Ramos cilíndricos, canaliculados, lenticelados, tomentosos a glabrescentes. Folhas imparipinadas; estípulas não observadas; pecíolo 15-19 mm compr., esparsamente tomentoso; raque $6,7-10 \mathrm{~cm}$ compr., esparsamente tomentosa; folíolos 7-13, 2,8-6,6 × 1,4-2,5 cm, alternos, elípticos, base obtusa, ápice agudo, retuso, face adaxial glabra, levemente tomentosa na nervura principal, face abaxial esparsamente tomentosa sobre a nervura principal, traços e pontuações translúcidas no limbo. Flores não observadas. Sâmaras, 5,4-6,1 ×1,7-2,1 cm, estípite 5-6 mm compr., base oblíqua, cálice persistente, ápice oblíquo, mucronado, glabras, douradas, região seminífera distal, 10-14 mm larg., enrugada, ala com nervura sub-mediana comprimida, 13-15 mm larg.; semente amarelo-clara.

Material examinado: trilha 8, 28.IX.2003, fr., F. L.R. Filardi et al. 322 (VIC).

Nome popular: bálsamo, cabreúva.

Amplamente distribuída nas Américas, assim como no Brasil, onde ocorre no nordeste, centro-oeste, sudeste e sul do país, ocupando áreas de floresta pluvial, floresta estacional semidecidual (Sartori 2000) e formações florestais do cerrado (Mendonça et al. 1998). Na EAVG, a espécie é rara e restrita à área de floresta estacional localizada próxima à várzea (trilha 8) (Fig. 1). A frutificação foi observada em setembro.
8. Ormosia Jacks., Trans. Linn. Soc. London 10: 358-362. 1811.

8.1 Ormosia fastigiata Tul., Arch. Mus. Par. 4: 108. 1844.

Fig. 3 h-k

Árvores ca. 9 malt. Ramos cilíndricos a levemente angulosos, velutinos. Folhas imparipinadas; estípulas lanceoladas, ca. $1 \mathrm{~cm}$ compr., tomentosas; pecíolo (1,5-) 3,8-6 cm compr., velutino; raque (7,2-) 10,5-18,3 (-22) cm compr., velutina; folíolos 7-9, 5,5-13,5 × 3,3-6 cm, opostos a subopostos, elípticos a amplamente elípticos, distais obovados, base obtusa a arredondada, ápice obtuso a acuminado, face adaxial glabra, face abaxial tomentosa, indumento mais denso sobre as nervuras. Flores não observadas. Legumes, 3-5,8 $\times 2,3-3 \mathrm{~cm}$, orbiculares ou constritos entre as sementes, base atenuada, ápice cuspidado, velutinos, castanhos a castanho-escuros; sementes 1-2, bicolores, vermelhas e pretas.

Material examinado: trilha 1, 3.V.2005, fr., F. L. R. Filardi et al. 584 (VIC); trilha 4, 24.IX.2002, fr., $F$. L. R. Filardi et al. 99 (VIC); trilha 5, 26.II.2003, fr., F. L. R. Filardi et al. 258 (VIC).

Nome popular: tento.

Restrita ao Brasil, a espécie é citada para os estados de Goiás, Mato Grosso, Minas Gerais, Rio de Janeiro, São Paulo, Paraná (Rudd 1954) e Bahia (Lewis 1987), ocupando áreas acima de $500 \mathrm{~m}$ de altitude (Rudd 1954), inclusive formações florestais do cerrado (Mendonça et al. 1998). A espécie é comum nas formações de cerrado da EAVG, sendo mais freqüente no cerrado sensu stricto limítrofe à várzea (trilha 4) e em uma das áreas de cerradão (trilha 5). Foram observados dois indivíduos de grande porte, com cerca de $18 \mathrm{~m}$ de altura e $170 \mathrm{~cm}$ de diâmetro, na "ilhota" que faz parte da trilha ao longo da margem mineira do reservatório (trilha 9) (Fig. 1). Pode ser utilizada para a recuperação de áreas degradadas, pois é capaz de estabelecer associação com bactérias para fixação de nitrogênio (Sprent 2001), sendo suas sementes muito utilizadas em trabalhos artesanais. A frutificação foi observada nos meses de fevereiro, maio e setembro. 
9. Platypodium Vog., Linnaea 11: 420. 1837.

9.1 Platypodium elegans Vog., Linnaea 11: 422.1837.

Fig. 3 1-n

Árvores 3,5-8 m alt. Ramos cilíndricos, canaliculados, lenticelados, puberulentos. Folhas imparipinadas; estípulas lineares, ca. $3 \mathrm{~mm}$ compr., tomentosas, caducas; pecíolo $1,4-2,2 \mathrm{~cm}$ compr., tomentoso; raque $(8,2-)$ 10,3-16 cm compr., tomentosa; folíolos 13-21, (2,5-) 3,2-4,8 × 1,3-2 cm, alternos, oblongos a elípticos, base oblíqua a obtusa, ápice emarginado, mucronulado, face adaxial glabra, face abaxial tomentosa. Inflorescências racemosas, axilares, terminais, pedúnculo 8 $19 \mathrm{~mm}$ compr., raque $9,8-12 \mathrm{~cm}$ compr., tomentosa; brácteas deltóides, ca. $3 \mathrm{~mm}$ compr., tomentosas; bractéolas ovadas, 1 na base do pedicelo, ca. $4 \mathrm{~mm}$ compr., 2 no ápice do pedicelo, ca. $2 \mathrm{~mm}$ compr., tomentosas. Flores zigomorfas, hipanto ca. $2 \mathrm{~mm}$ compr.; pedicelo 5-8 mm compr.; cálice campanulado, 8-10 × 6-7 mm, 5-laciniado, internamente seríceo, externamente glabro; corola amarela, glabra; vexilo $14 \times 17-20 \mathrm{~mm}$, base truncada, unguícula ca. $4 \mathrm{~mm}$ compr., ápice retuso; alas $15-17 \times 8 \mathrm{~mm}$, base oblíqua, unguícula ca. $6 \mathrm{~mm}$ compr.; pétalas da carena 11-12×6 mm, base oblíqua, unguícula ca. $5 \mathrm{~mm}$ compr.; androceu poliadelfo, ca. $13 \mathrm{~mm}$ compr., 4+1+4+1 estames, anteras com deiscência longitudinal; ovário ca. $4 \mathrm{~mm}$ compr., glabro, seríceo na margem, estípite ca. $6 \mathrm{~mm}$ compr.; estilete ca. 3,5 mm compr.; estigma inconspícuo, crestado. Sâmaras, 6,9-8 × 1,8-2,6 cm, estípite 1-1,3 cm compr., base atenuada, cálice persistente, ápice obtuso, glabras, castanho-claras, região seminífera distal, 1,8-2 cm larg., castanhoescura, ala 2,3-2,6 cm larg.; semente castanho-alaranjada.

Material examinado: trilha 1, 25.IX.2002, fr., F.L.R. Filardi et al. 100 (VIC); idem, fl., F. L. R. Filardi et al. 102 (VIC); trilha 2, 27.II.2003, fr., F. L. R. Filardi et al. 290 (VIC); trilha 4, 6.V.2004, fr., F. L. R. Filardi et al 509 (VIC); trilha 5, 29.IX.2003, fl., F. L. R. Filardi et al. 334 (VIC).

Nome popular: jacarandá-branco.

Apresenta distribuição neotropical, sendo considerada uma espécie generalista (Morim
2006) e no Brasil, ocorre do Piauí até Goiás, Mato Grosso do Sul, São Paulo (Lorenzi 2002a) e Minas Gerais, ocupando áreas do domínio da mata atlântica (Bortoluzzi et al. 2004), de cerrado (Ratter et al. 2003) e caatinga (Lewis 1987). A espécie é comum nas formações de cerradão da EAVG (trilha 5), porém é mais freqüente na área de cerrado sensu stricto em estágio mais avançado de regeneração (trilha 1). Floresceu em setembro e a frutificação foi observada entre fevereiro e maio, apresentando flores e frutos em setembro.

10. Pterodon Vog., Linnaea 11: 384. 1837.

10.1 Pterodon emarginatus Vog., Linnaea 11: 384. 1837. Fig. 3 o-q

Árvores 12-20 m alt. Ramos cilíndricos, tomentosos a glabrescentes. Folhas imparipinadas, com apêndice terminal; estípulas não observadas; pecíolo (1-) 1,6-2 cm compr., tomentoso; raque 11-17 cm compr., tomentosa; folíolos 23-37, 22-57 × 7-16 mm, opostos a subopostos, oblongos, base obtusa a oblíqua, ápice emarginado, mucronulado, face adaxial ciliada a esparsamente ciliada, face abaxial tomentosa a esparsamente tomentosa. Inflorescências em panículas, axilares, terminais, pedúnculo 11-13 mm compr., raque 7,2-10,5 cm compr., tomentosa; brácteas e bractéolas não observadas. Flores zigomorfas, hipanto ca. $1 \mathrm{~mm}$ compr.; pedicelo ca. $5 \mathrm{~mm}$ compr.; 2 sépalas adaxiais petalóides e 3 sépalas abaxiais reduzidas, ca. $8 \times 4 \mathrm{~mm}$, internamente puberulentas, externamente com pontos glandulares; corola branca, glabra; vexilo ca. 9 $\times 8 \mathrm{~mm}$, base atenuada, unguícula ca. $1,5 \mathrm{~mm}$ compr., ápice emarginado, apêndice acicular entre os lobos; alas ca. $11 \times 4 \mathrm{~mm}$, base auriculada, unguícula ca. $1 \mathrm{~mm}$ compr., ápice emarginado, apêndice acicular entre os lobos; pétalas da carena ca. $9 \times 3 \mathrm{~mm}$, base auriculada, unguícula ca. $1 \mathrm{~mm}$ compr., ápice com apêndice acicular; androceu monadelfo, ca. $7 \mathrm{~mm}$ compr., 10 estames, anteras com deiscência longitudinal; ovário ca. 1,5 mm compr., glabro, estípite ca. $3 \mathrm{~mm}$ compr.; estilete ca. $3 \mathrm{~mm}$ compr.; estigma inconspícuo, lobado. Criptossâmaras, 4,4-5,3 $\times 2,7-3,3 \mathrm{~cm}$, elípticas, base obtusa a atenuada, 
ápice obtuso, glabras, exocarpo deiscente, castanho-escuro, endocarpo indeiscente, castanho-claro, região seminífera central, 1,3-1,6 cm larg.; semente castanho-escura.

Material examinado: trilha 2, 24.II.2003, fr., F. L. R. Filardi et al. 211 (VIC); idem, 29.IX.2003, fl.fr., F. L. R. Filardi et al. 328 (VIC); trilha 8, 18.IX.2002, fl., F. L. R. Filardi et al. 29 (VIC).

Nome popular: sucupira-amarela.

A espécie é nativa da Bolívia e do Brasil (ILDIS 2005), onde ocorre em Goiás, Mato Grosso do Sul, Minas Gerais e São Paulo (Lorenzi 2002a), principalmente no cerrado (Ratter et al. 2003). Na EAVG, a espécie é pouco freqüente, mas ocorre tanto em áreas de floresta estacional semidecidual (trilha 8), quanto em cerrado sensu srticto (trilha 2), sendo também observados indivíduos nas áreas de cerradão. Suas sementes são utilizadas na medicina popular como fortificante. Floresce de agosto a outubro e frutifica de setembro a fevereiro.

11. Sesbania Scop., Introd. Hist. Nat. 308309. 1777.

11.1 Sesbania virgata (Cav.) Pers., Syn. Pl. 2:316. 1807.

Fig. 3 r-t

Arbustos 1,5-3 m alt. Ramos cilíndricos, lenticelados, ciliados a glabrescentes. Folhas paripinadas; estípulas lanceoladas, 1-3 mm compr., seríceas; pecíolo 9-14 mm compr., seríceo; raque $12-22,3 \mathrm{~cm}$ compr., serícea; folíolos 17-22 pares, 21-32 ×6-10 mm, opostos a subopostos, oblongos a elípticos, base obtusa, ápice obtuso, mucronulado, face adaxial glabra, face abaxial serícea. Inflorescências racemosas, axilares, pedúnculo 8-17 mm compr., raque 4,27,4 cm compr. serícea; brácteas não observadas, bractéolas lanceoladas, ca. 1,8 $\mathrm{mm}$ compr., seríceas. Flores zigomorfas, hipanto ca. $2 \mathrm{~mm}$ compr.; pedicelo ca. 4,5 mm compr.; cálice campanulado, ca. $4 \times 4,5 \mathrm{~mm}$, 5-laciniado, seríceo; corola amarelo-clara, glabra; vexilo ca. $9 \times 9 \mathrm{~mm}$, base truncada, unguícula ca. $2 \mathrm{~mm}$ compr., 2 apêndices na $1 / 2$ da unguícula, ápice obcordato, recurvado, estrias verdes dorsais; alas ca. $8 \times$ $3 \mathrm{~mm}$, base atenuada, unguícula ca. $4 \mathrm{~mm}$ compr.; pétalas da carena ca. $7 \times 3,5 \mathrm{~mm}$, base atenuada, unguícula ca. $5 \mathrm{~mm}$ compr.; androceu diadelfo, ca. $9 \mathrm{~mm}$ compr., 9+1 estames, anteras com deiscência longitudinal; ovário ca. $8 \mathrm{~mm}$ compr., glabro, estípite ca. 2,5 mm compr.; estilete ca. $3 \mathrm{~mm}$ compr.; estigma inconspícuo, clavado. Legumes nucóides, 4-5,7×0,7-1 cm, retangulares, angulosos, estípite 6-7 mm compr., base atenuada, ápice agudo, margem constrita longitudinalmente, glabros, castanho-escuros; sementes 5-9, castanhas.

Material examinado: trilha 3, 24.II.2003, fr., F. L. R. Filardi et al. 206 (VIC); trilha 8, 10.XII.2003, fl., F. L. R. Filardi et al. 426 (VIC).

Nome popular: mangerioba.

Restrita à América do Sul (ILDIS 2005), no Brasil ocorre no Distrito Federal, Mato Grosso do Sul, Minas Gerais, Rio de Janeiro, São Paulo e Rio Grande do Sul (Monteiro 1994). Citada para áreas alteradas do bioma cerrado (Mendonça et al. 1998), apresenta grande vigor nos estágios iniciais de sucessão pela capacidade de associação com bactérias diazotróficas (Sprent 2001). Na EAVG, a espécie é comum e ocorre ao longo de estradas de terra que delimitam áreas de cerrado sensu stricto (trilha 3) e de floresta estacional semidecidual (trilha 8). Floresceu em dezembro e frutificou em fevereiro.

\section{Agradecimentos}

As autoras agradecem a CEMIGANEEL pelo financiamento do projeto e pela bolsa concedida à primeira autora; à Usina Hidrelétrica de Volta Grande pela estrutura física concedida na Estação Ambiental e atenção de seus funcionários; ao Reinaldo A. Pinto pelas ilustrações; aos amigos Sebastião L. Faria e Carlos Matheus S. Paixão pelo auxílio nos trabalhos de campo e aos doutores Haroldo C. de Lima (JBRJ) e Luciano P. de Queiroz (UEFS), bem como aos revisores, pelas valiosas sugestões.

\section{REFERÊnCIAS BibLIOGRÁFICAS}

Barroso, G. M.; Morim, M. P.; Peixoto A. L. \& Ichaso, C. L. F. 1999. Frutos e sementes: morfologia aplicada à sistemática de dicotiledôneas. Editora UFV, Viçosa, 443p. 
Bortoluzzi, R. L. C.; Carvalho-Okano, R. M.; Garcia, F. C. P. \& Tozzi, A. M. G. A. 2004. Leguminosae Papilionoideae no Parque Estadual do Rio Doce, Minas Gerais, Brasil. II: árvores e arbustos escandentes. Acta Botanica Brasilica 18(1): 49-71.

Bosquetti, L. B. 2004. Caesalpinioideae (Leguminosae) no Parque Estadual do Rio Doce, Minas Gerais, Brasil. Dissertação de Mestrado. Universidade Federal de Viçosa, Viçosa, 86p.

Carvalho, A. M. 1997. A synopsis of the genus Dalbergia (Fabaceae: Dalbergieae) in Brazil. Brittonia 49(1): 87-109.

César, E. A.; Juchum, F. S. \& Lewis, G. P. 2006. Lista preliminar da família Leguminosae na Região Nordeste do Brasil - Série Repatriamento de Dados do Herbário de Kew para a flora do Nordeste do Brasil. Vol. 2. Royal Botanic Gardens, Kew, 209p.

Cordeiro, L. 2002. Fixação de nitrogênio em leguminosas ocorrentes no cerrado. In: Klein, A. (ed.). Eugen Warming e o cerrado brasileiro: um século depois. UNESP, São Paulo. Pp. 131-145.

Coutinho, L. M. 2002. O bioma cerrado. In: Klein, A. L. (ed.). Eugen Warming e o cerrado brasileiro: um século depois. UNESP, São Paulo. Pp. 77-92.

CPETEC/INPE. 2006. http://www.cptec.inpe.br/ clima/monit/monitor_brasil.shtml

Deharo, E.; Bourdy, G.; Quenevo, C.; Muñoz, V.; Ruiz, G. \& Sauvain, M. 2001. A search for natural bioactive compounds in Bolívia through a multidisciplinary approach. Part. V. Evaluation of the antimalarial activity of plants used by the Tacana Indians. Journal of Ethnopharmacology 77: 91-98.

Drummond, G. M.; Martins, C. S.; Machado, A. B. M.; Sebaio, F. A. \& Antonini, Y. 2005. Biodiversidade em Minas Gerais: um atlas para sua conservação. Fundação Biodiversitas, Belo Horizonte, 222p.

Ducke, A. 1949. As leguminosas da Amazônia brasileira. Boletim técnico do Instituto Agronômico Norte 18: 4-248.
Durigan, G.; Baitelo, J. B.; Franco, G. A. D. C. \& Siqueira, M. F. 2004. Plantas do cerrado paulista: imagens de uma paisagem ameaçada. Páginas \& Letras Editora e Gráfica, São Paulo, 475p.

Dutra, V. F. 2005. Leguminosae Adans. nos campos rupestres do Parque Estadual do Itacolomi, MG, Brasil: florística, preferência por habitat, aspectos reprodutivos e distribuição geográfica. Dissertação de Mestrado. Universidade Federal de Viçosa, Viçosa, 171p.

Eiten, G. 1972. The Cerrado vegetation of Brazil. Botanical Review 38 (2): 201-341.

Fidalgo, O. \& Bononi, V. L. R. 1984. Técnicas de coleta, preservação e herborização do material botânico. Instituto de Botânica (manual 4), São Paulo, 61p.

ILDIS. 2005. International Legume Database and Information Science. http:// www.ildis.org

Laca-Buendia, J. P. \& Brandão, M. 1995. Composição florística e análise fitossociológica do Cerrado em Minas Gerais I: Alto Paranaíba, Mata da Corda e parte do Planalto de Araxá. Daphne 5(1): 7-18.

Lewis, G. P. 1987. Legumes of Bahia. Royal Botanic Gardens, Kew, 369p.

; Schrire, B.; Mackinder, B. \& Lock, M. 2005. Legumes of the world. Royal Botanic Gardens, Kew, 577p.

Lima, H. C. 1988. Centrolobium Martius ex Bentham (Leguminosae-Papilionoideae) estudo taxonômico das espécies brasileiras extra-amazônicas. Arquivos do Jardim Botânico do Rio de Janeiro 27: 177-191.

1995. Leguminosas da Flora Fluminensis - J. M. da C. Vellozo - Lista atualizada das espécies arbóreas. Acta Botanica Brasílica 9(1): 123-146.

Lima, L. C. P. 2006. Leguminosae Adans. nas florestas estacionais do Parque Estadual do Itacolomi, Minas Gerais, Brasil: taxonomia, preferência por habitat, distribuição geográfica e similaridade florística. Dissertação de Mestrado. Universidade Federal de Viçosa, Viçosa, 134p. 
Lorenzi, H. 2002a. Árvores brasileiras: manual de identificação e cultivo de plantas arbóreas nativas do Brasil. vol. 1, $4^{\circ} \mathrm{ed}$. Editora Plantarum, São Paulo, 368p. 2002b. Árvores brasileiras: manual de identificação e cultivo de plantas arbóreas nativas do Brasil. vol. 2, $2^{\circ}$ ed. Editora Plantarum, São Paulo, 368p.

Mendonça Filho, C. V. 1996. Braúna, Angico, Jacarandá e outras Leguminosas de Mata Atlântica - Estação Biológica de Caratinga, Minas Gerais. Fundação Botânica Margaret Mee / Fundação Biodiversitas, Belo Horizonte, 100p.

Mendonça, R. C.; Felfili, J. M.; Walter, B. M. T.; Silva Júnior, M. C.; Rezende, A. V.; Filgueiras, T. S. \& Nogueira, P. E. 1998. Flora vascular do Cerrado. In: Sano, M. \& Almeida, S. P. (eds.). Cerrado: ambiente e flora. EMBRAPA-CPAC, Planaltina. Pp. 287-556.

Monteiro, R. 1994. The species of Sesbania Scop. (Leguminosae) in Brazil. Arquivos de Biologia e Tecnologia 37(2): 309-331.

Morim, M. P. 2006. Leguminosae arbustivas e arbóreas da Floresta Atlântica do Parque Nacional do Itatiaia, sudeste do Brasil: padrões de distribuição. Rodriguésia 57(1): 27-45.

Myers, N.; Mittermeier, R. A.; Mittermeier, C. G.; Fonseca, G. A. B. \& Kent, J. 2000. Biodiversity hotspots for conservation priorities. Nature 403: 853-858.

Nunes, S. R. D. F. S. 2003. As Mimosoideae (Leguminosae) no Parque Estadual do Rio Doce, Minas Gerais, Brasil. Dissertação de Mestrado. Universidade Federal de Viçosa, Viçosa, 106p.

Pennington, R. T.; Prado, D. E. \& Pendry, C. A. 2000. Neotropical seasonally dry forests and Quaternary vegetation changes. Journal of Biogeography 27: 261-273.

Polhill, R. M. \& Raven, P. H. 1981. Advances in Legume Systematics. Royal Botanic Gardens, Kew, 1049p.

Queiroz, L. P. 2004. Flora de Grão Mogol, Minas Gerais: Leguminosae. Boletim de Botânica da Universidade de São Paulo 22: 242-265.
Radford, A. E.; Dickison, W. C.; Massey, J. R. \& Bell, C. R. 1974. Vascular plant systematics. Harper \& Row, New York, 891p.

Ratter, J. A.; Ribeiro, J. F. \& Bridgewater, S. 1997. The Brazilian Cerrado vegetation and threats to its biodiversity. Annals of Botany 80: 223-230.

; Bridgewater, S. \& Ribeiro, J. F. 2003. Analysis of the floristic composition of the Brazilian Cerrado vegetation III. Comparison of the woody vegetation of 376 areas. Edinburgh Journal of Botany 60(1): 57-109.

Rudd, V. E. 1954. The American species of Ormosia (Leguminosae). Contributions from the National Herbarium 32(5): 279-388.

Sartori, A. L. B. \& Tozzi, A. M. G. A. 1998. As espécies de Machaerium Pers. (Leguminosae-Papilionoideae-Dalbergieae) ocorrentes no estado de São Paulo. Revista Brasileira de Botânica 21(3): 211-246.

2000. Revisão taxonômica e estudos morfológicos de Myrocarpus Allemão, Myroxylon L. e Myrospermum Jacq. (Legumonosae Papilionoideae Sophoreae). Tese de Doutorado. Universidade Estadual de Campinas, Campinas, 268p.

Sprent, J. I. 2001. Nodulation in Legumes. Royal Botanic Gardens, Kew, 146p.

Vaz, M. M.; Torquato, V. C. \& Barbosa, N. D. C. 2000. Guia ilustrado de peixes da bacia do Rio Grande. CEMIG/CETEC, Belo Horizonte, 144p.

Warming, E. \& Ferri, M. G. 1973. Lagoa Santa e a vegetação de cerrados brasileiros. EDUSP, São Paulo, 362p.

Yakovlev, G. P. 1969. A review of Sweetia \& Acosmium. Notes from Royal Botanical Garden of Edinburgh 29: 347-355.

Zappi, D. C.; Lucas, E.; Stannard, B. L.; Lughadh, E. N. J. R.; Queiroz, L. P.; Atkins, S.; Hind, D. J. N.; Harley, R. M. \& Carvalho, A. M. 2003. Lista das plantas vasculares de Catolés, Chapada Diamantina, Bahia, Brasil. Boletim de Botânica da Universidade de São Paulo 21(2): 345-389. 